\title{
Simulation Analysis of Hydraulic Lifting Mechanism of a Forklift Wang $\mathrm{Yao}^{1}$,Bai Yan ${ }^{2,{ }^{*}}$, Zhang Qijiu ${ }^{1}$, Gan Xinji ${ }^{1}$ \\ ${ }^{1}$ School of Mechanical Engineering, Beihua University, Jilin, China \\ ${ }^{2}$ Engineering Training Center, Beihua University, Jilin, China \\ *Corresponding author
}

Keywords: forklift; lifting mechanism; simulation; MATLAB

\begin{abstract}
Lifting action of forklift is the most common working condition. In this paper, the structure of the hydraulic lifting system of forklift truck is analyzed in detail and the mathematical model is established. On this basis, the MATLAB simulation model of forklift lifting system is established. The simulation results show that the energy consumption(149706J) and efficiency (49.05\%) under the rated load and rated lift height. Through the analysis and research of the energy consumption and efficiency of forklift truck lifting system, it lays a theoretical foundation for the future research of forklift truck energy saving.
\end{abstract}

\section{Introduction}

Forklifts include upright mounting systems, walking systems, braking systems, and steering systems. The lifting system is one of the most important parts of the forklift truck because the lift is the most common working condition [1]. Its efficiency directly affects the performance of the forklift, and it is also the main performance index of the forklift. At present, the hydraulic lifting system is used to drive the fork lift. Therefore, the study of analyzing and studying the energy consumption of forklift lifting mechanism has great significance [2-4].

Hydraulic transmission system has the advantages of stable transmission, large load capacity, strong anti overload ability and easy to realize automatic control. Hydraulic drive is widely used in modern forklift truck lifting system and steering system. At present, the hydraulic drive forklift lifting system can be divided into two level standard upright mounting, two level free upright mounting and so on.

\section{Setting of the Simulation Parameter}

Load Physical Parameters. In the process of simulation [5], the weight and the gravity of the fork are equivalent to the inner upright mounting and the physical parameters are shown in Table 1.

Table 1 simulation parameter

\begin{tabular}{cc}
\hline item & value \\
\hline Equivalent quality of inner upright mounting & $6175 \mathrm{~kg}$ \\
Rise height of inner upright mounting & $1.5 \mathrm{~m}$ \\
$\begin{array}{c}\text { Maximum rise speed of inner upright mounting } \\
\text { Expected rising acceleration of inner upright } \\
\quad \begin{array}{c}\text { mounting } \\
\text { The friction force of guide rail of inner and } \\
\text { outer upright mounting }\end{array}\end{array}$ & $0.15 \mathrm{~m} / \mathrm{s}$ \\
\hline
\end{tabular}

Main Parameters of Hydraulic Lifting System. According to the lifting process of the forklift, the goods will accelerate steadily in 0 to 4 seconds, and the goods will rise at a constant speed within 4 to 10 seconds, and the goods will decelerate steadily in 10 to 14 seconds. Hydraulic flow source, according to the speed planning requirements, the provision of hydraulic oil. Control the 
throttle opening within 14 to 25 seconds to lower the load.

\section{Mathematical Model of Hydraulic Lifting Mechanism of Forklift}

The dynamic model during the lifting of upright mounting is:

$$
F-\left(M+M_{1}+\frac{1}{2} M_{2}+\frac{1}{2} M_{3}\right) g-F_{f}=\frac{1}{2} \varsigma\left(M+M_{1}+\frac{1}{2} M_{2}+\frac{1}{2} M_{3}\right) a
$$

In the formula: $F$-Force of lifting cylinder, piston rod, N;

$M$-Load quality, kg;

$M_{1}$-Fork quality, kg;

$M_{2}$-Inner upright mounting quality, kg;

$M_{3}$-Piston rod quality, kg;

$F_{\mathrm{f}}$-Friction between inner and outer upright mounting, N;

$a$-Fork and load lifting acceleration, $\mathrm{m} / \mathrm{s}^{2}$;

$\varsigma$-Rotary mass transfer coefficient of the upright mounting.

The force balance equation of the lifting cylinder is:

$$
F-p_{1} A_{1}=\frac{1}{2} M_{3} a+B v+F_{f 1}
$$

In the formula: $p_{1}$-Pressure of lifting cylinder rodless chamber, $\mathrm{Pa}$;

$A_{1}$-Effective area of the piston, $\mathrm{m}^{2}$;

$B$-Viscous damping coefficient between piston and hydraulic cylinder, $\mathrm{N} \cdot \mathrm{s} / \mathrm{m}$;

$v$-Rising speed of the inner upright mounting, $\mathrm{m} / \mathrm{s}$;

$F_{\mathrm{f} 1}$ - The friction between the piston and the hydraulic cylinder, $\mathrm{N}$.

The torque balance equation of the hydraulic motor is:

$$
D_{m} p_{2}=J_{m} \dot{\omega}_{m}+B_{m} \omega_{m}+T_{m f}
$$

In the formula: $D_{m}$ - Radian displacement of the hydraulic motor, $\mathrm{m}^{3} / \mathrm{rad}$;

$p_{2}$ - Inlet pressure of the hydraulic motor, $\mathrm{Pa}$;

$J_{m}$ - The moment of inertia of the hydraulic motor, $\mathrm{kg} \cdot \mathrm{m}^{2}$;

$\omega_{m}$ - Angular speed of the hydraulic motor, $\mathrm{s}^{-1}$;

$B_{m}$-Rotational viscous damping coefficient of the hydraulic motor, $\mathrm{N} \cdot \mathrm{s} / \mathrm{m}$;

$T_{m f}$-Frictional torque of the hydraulic motor, $\mathrm{N} \cdot \mathrm{m}$.

\section{Simulation Model of Hydraulic Lifting Mechanism Based on MATLAB}

The controllable flow source (hydraulic pump) is controlled by the lifting signal, and the output flow is determined according to the lifting signal. In the rising stage, two-position three-way valve P-A connection, throttle valve closed, the hydraulic oil flows through the one-way valve, single acting hydraulic cylinder lifting heavy inflows; in the decline phase, two-position three-way valve A-T connection, the throttle valve maintain a certain degree opening, the hydraulic oil flows from the single acting hydraulic cylinder, the flow through the throttle valve, back to tank. The flow, working pressure, moving displacement, velocity and acceleration of the internal pressure frame are outputted and recorded in matrix form respectively. Simulation model of hydraulic lifting mechanism based on MATLAB is shown in Fig. 1. 


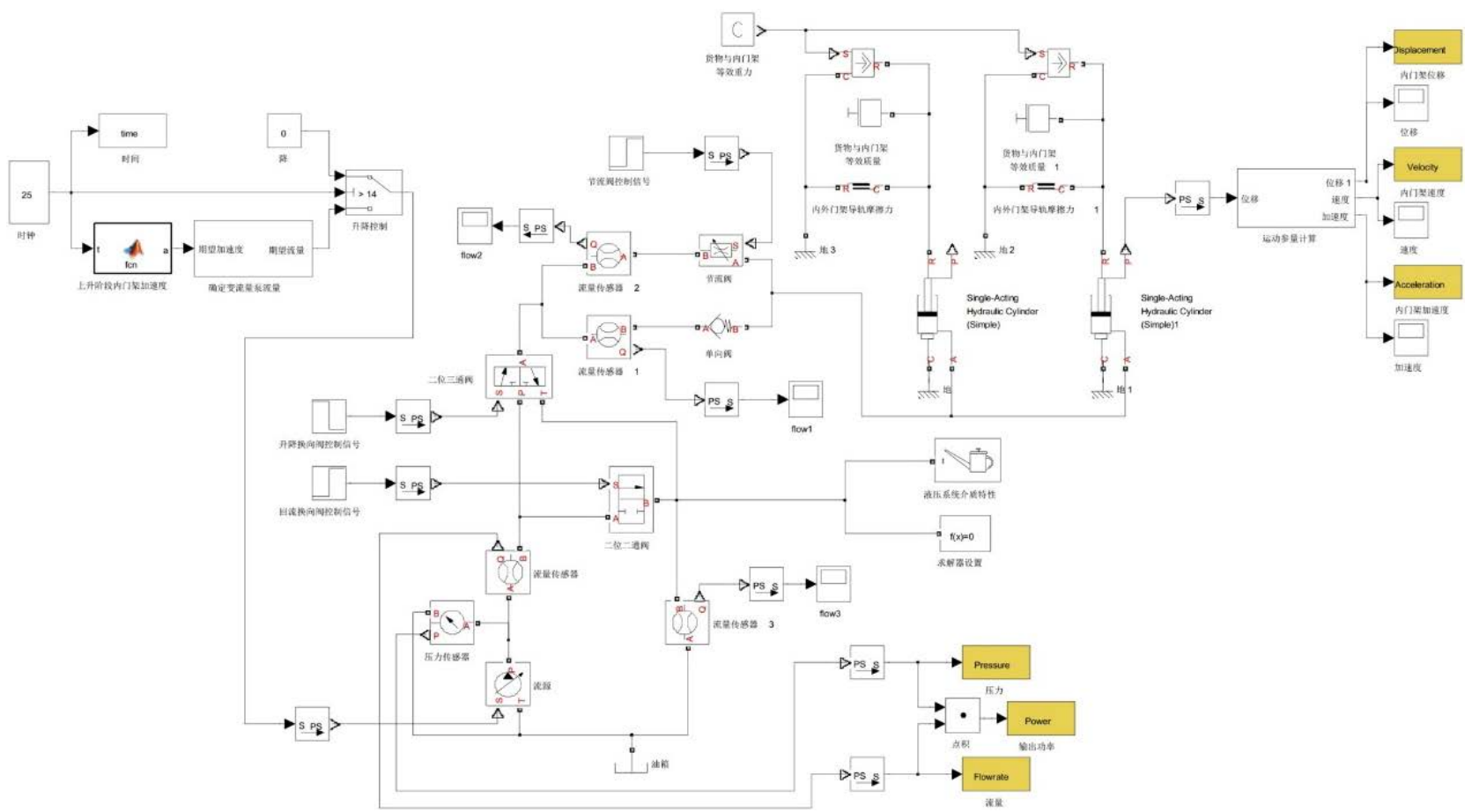

Fig. 1 Simulation model of hydraulic lifting mechanism based on MATLAB

\section{Simulation Results Analysis}

The output data was collated and the curve of the inner upright mounting, the output pressure, the flow rate and the output power of the hydraulic flow source was obtained, hydraulic Lifting System Simulation Curve is shown in the fig. 2 and fig. 3.

The simulation results showed that when the lifting height is 3 meters and the load is 3 tons, the working efficiency of the hydraulic drive forklift lifting mechanism is $49.05 \%$, as shown in the table 2.
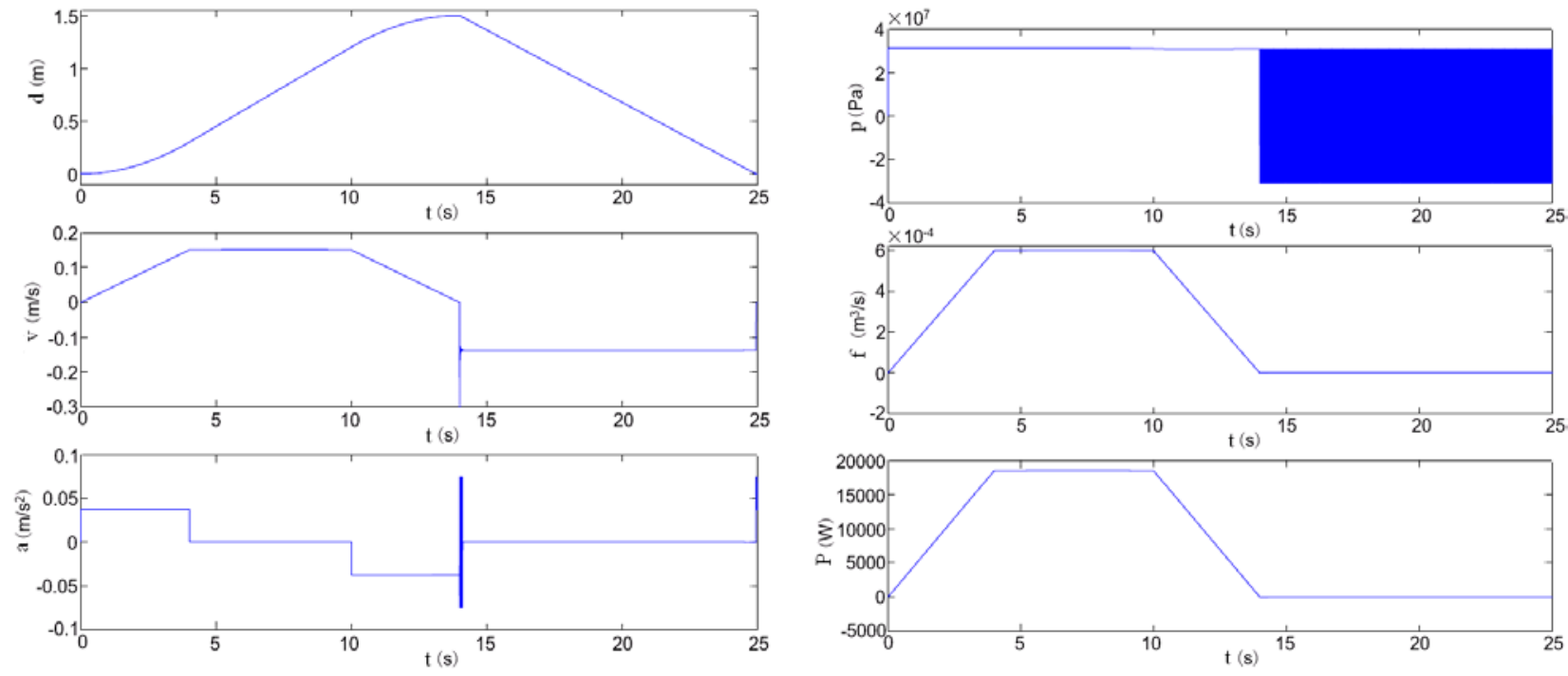

Fig. 2 moving curve of inner upright mounting

Fig. 3 The output pressure, flow rate and output power curve of hydraulic lifting system Table2 Energy consumption and efficiency of hydraulic lifting system

\begin{tabular}{cc}
\hline item & value \\
\hline Energy consumption of hydraulic lifting system & $149706 \mathrm{~J}$ \\
Hydraulic lift system efficiency & $49.05 \%$ \\
\hline
\end{tabular}




\section{Conclusion}

In this paper, the structure of forklift truck frame system is analyzed firstly. Then the mathematical model of hydraulic lifting mechanism is established. The MATLAB simulation model of the forklift hydraulic lifting mechanism is established. Through analysis, we can see that the energy consumption is $149706 \mathrm{~J}$ and the efficiency is $49.05 \%$ when the single lifting process is completed under the rated load and rated lifting height.

\section{Acknowledgment}

The research is funded by the project development plan of science and technology in Jilin Province (20160418024FG).

\section{Reference}

[1] Wang Y, Zhao D, Wang L, et al. Dynamic simulation and analysis of the elevating mechanism of a forklift based on a power bond graph[J]. Journal of Mechanical Science \& Technology, 2016, 30(9):4043-4048.

[2] Yu S B, Wu Z Y, Xu Z. The Simulation Analysis of Ball Screw Pair Contact Characteristics Based on ADAMS[M]. 2012.

[3] K. Baša, A. Žemva. Simulation and verification of a dynamic model of the electric forklift truck[J]. Intelligent Automation \& Soft Computing,2011,17 (1),13-30.

[4] Hosseinzadeh E, Rokni M, Advani S G, et al. Performance simulation and analysis of a fuel cell/battery hybrid forklift truck [J]. International Journal of Hydrogen Energy, 2013, 38(11): 4241-4249.

[5] Lin Shuiqiu. Modeling and Simulation of Hydraulic Controlled System Based on Simulink[J]. Journal of Zhangzhou Normal University(Natural Science),2006,3:53-56. 